\title{
Evaluation of two novel techniques for increasing radial artery size: a pilot study utilizing volunteers
}

\author{
Evan Shao, MD • Himat Vaghadia, MD • Neil Ramsay, MD • \\ Raymond Tang, MD $\cdot$ Andrew Sawka, MD
}

Received: 22 December 2016/Revised: 1 March 2017/Accepted: 10 March 2017/Published online: 15 March 2017

(C) Canadian Anesthesiologists' Society 2017

\section{To the Editor,}

Arterial cannulation is a common procedure performed during the perioperative period. Cannulation of the radial artery, however, has proved difficult despite ultrasonographic guidance. ${ }^{1}$ Maheshwari et al. proposed two novel techniques for increasing the radial artery diameter, both of which amplify the characteristics of blood flow through the artery. ${ }^{2}$ We investigated whether these two novel methods do indeed increase radial artery size.

This observational study was conducted at Vancouver General Hospital and was approved by the Clinical Research Ethics Board of the University of British Columbia (September 14, 2016: \#H16-01730). Informed written consent was obtained from 35 healthy, American Society of Anesthesiologists I-II volunteers. We excluded volunteers with previous surgery to the radial or ulnar artery and those with a positive Allen's test.

The radial artery was measured at the same location under three study conditions: (1) controls: no compression (Figure A); (2) radial artery compression: the radial artery was mechanically compressed distally (Figure B); (3) ulnar artery compression: the ipsilateral ulnar artery was mechanically compressed approximately $1-2 \mathrm{~cm}$ proximal to the distal wrist crease (Figure C). Using a 13-6 MHz linear transducer (Sonosite, Fujifilm) the radial artery was visualized $2-3 \mathrm{~cm}$ proximal to the radial styloid process. A second $13-6 \mathrm{MHz}$ linear transducer was used to compress the radial and ulnar artery mechanically. The order in

E. Shao, MD $(\varangle) \cdot$ H. Vaghadia, MD · N. Ramsay, MD .

R. Tang, MD - A. Sawka, MD

Department of Anesthesiology, Pharmacology and Therapeutics,

University of British Columbia, Vancouver, BC, Canada

e-mail: evanshao@alumni.ubc.ca which these methods were tested was randomized. A second investigator, who was blinded to which method was used, measured the vertical radial artery diameter and recorded the results. Measurements were repeated on both the right and left wrists.

In all, 35 volunteers participated (22 women, 13 men). Their mean (SD) weight and systolic and diastolic blood pressures were 69.7 (14.5) kg, 130 (17) $\mathrm{mmHg}$, and 73 (13) $\mathrm{mmHg}$, respectively.

The radial artery was easily identified on ultrasonography in all of the study subjects. The mean (SD) diameter of the uncompressed radial artery was 2.09 $\mathrm{mm}(0.35)$. Distal radial artery compression resulted in a mean increase in the radial artery diameter of $0.10 \mathrm{~mm}$ (95\% confidence interval $[\mathrm{CI}], 0.06$ to $0.15 ; P<0.01$ ). There was no increase in the radial artery diameter when the ulnar artery was compressed $(0.07 \mathrm{~mm} ; 95 \% \mathrm{CI}, 0.02$ to $0.12 ; P=0.06$ ).

We showed that compression of the distal radial artery increased the diameter of the radial artery. In contrast, compression of the ulnar artery did not influence the diameter of the ipsilateral radial artery. Although the radial artery diameter increase was statistically significant, the clinical significance of this change is uncertain. We believe that this small increase would not change the success rate of arterial cannulation with ultrasonography in patients comparable to these healthy volunteers with average size or larger arteries. It is unclear if the same relative increase of arterial size could be extrapolated to anatomically small, diseased, or physiologically stressed arteries, where this maneuver might be of greatest benefit. One may speculate that the back-pressure from distal radial artery occlusion might make the arterial pulsations more palpable and facilitate arterial line insertion in cases where ultrasonography is unavailable. Further studies are 


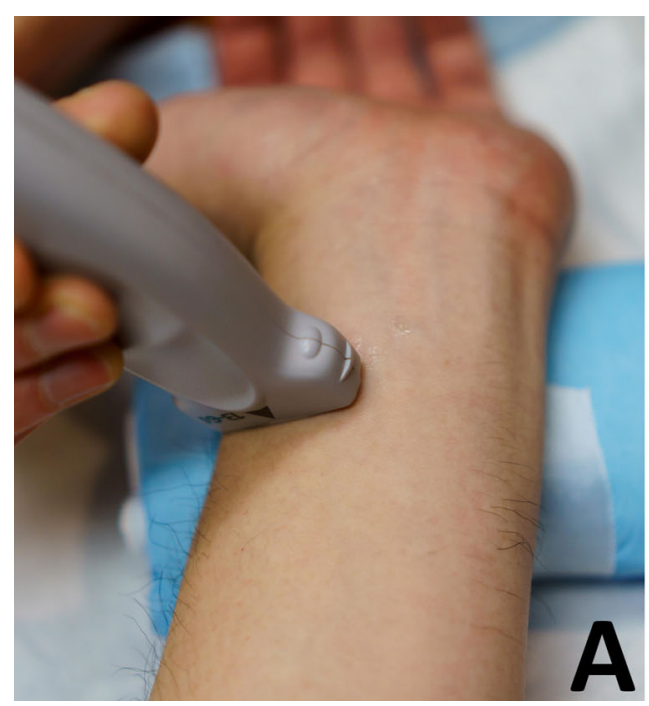

Figure Radial artery measurement using ultrasonography without arterial compression (A), with distal radial artery compression (B), and with ulnar artery compression $(\mathrm{C})$. The radial artery is measured

required to determine if distal radial artery compression will increase successful arterial cannulation in the population and circumstances of interest.

Acknowledgement The authors thank Boris Kuzeljevic for his excellent work with statistical consultation and analysis.

\section{Conflicts of interest None declared.}

Editorial responsibility This submission was handled by Dr. Gregory L. Bryson, Deputy Editor-in-Chief, Canadian Journal of Anesthesia.

Funding sources This work was supported by Department of Anesthesiology funding only

\section{Associations None.}

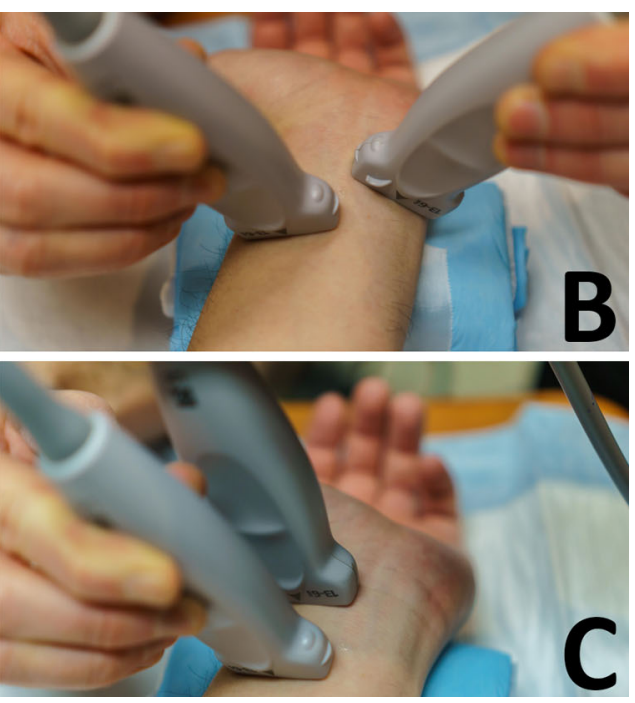

at the same location $(2-3 \mathrm{~cm}$ proximal to the radial styloid process) for all three conditions. The ipsilateral ulnar artery was mechanically compressed approximately $1-2 \mathrm{~cm}$ proximal to the distal wrist crease

\section{References}

1. Kotowycz MA, Johnston KW, Ivanov J, et al. Predictors of radial artery size in patients undergoing cardiac catheterization: insights from the Good Radial Artery Size Prediction (GRASP) study. Can J Cardiol 2014; 30: 211-6.

2. Maheshwari P, Kelsheimer B, Maheshwari P. Novel techniques for increasing the size of the radial artery during ultrasound-guided cannulation. Can J Anesth 2015; 63: 499-500. 